\title{
DEPRESSION IN MULTIPLE SCLEROSIS - REVIEW
}

\author{
Smaranda Maier', Rodica Balasa', Mircea Buruian², Anca Maier ${ }^{3}$, Zoltan Bajko1 \\ ${ }^{1}$ Department of Neurology, University of Medicine and Pharmacy, Targu Mures \\ ${ }^{2}$ Department of Radiology, University of Medicine and Pharmacy, Targu Mures \\ ${ }^{3}$ Department of Cardiology, University of Medicine and Pharmacy Targu Mures
}

\begin{abstract}
Depression is one of the most important psychiatric comorbidity in multiple sclerosis and is associated with increased disability and poor quality of life. The diagnosis is challenging because of the overlapping symptomatology. The pathogenesis is complex and controversial, the incidence is high, but is frequently under-diagnosed and under-treated.

The aim of this article is to review the most important aspects of depression in multiple sclerosis as: epidemiology, pathogenesis, assessment, correlates with disability, cognition, fatique, quality of life, suicide, the relationship with the immunomodulatory therapy, neuroimaging and treatment options.
\end{abstract}

Keywords: multiple sclerosis, depression

\section{INTRODUCTION}

Depression is the most prevalent psychiatric disease worldwide and is associated with disability and poor quality of life, has a negative impact on an individual's overall well-being, including academic and occupational achievements, interpersonal relationships, social activity and daily functioning. It is characterized by sad mood, loss of interest in usual activities, sleep disturbances, fatigue, irritability, reduced appetite, negative self-image, reduced concentration and suicidal ideation (DSM IV). $(1,2)$

Depression has a high prevalence in the general population, but it is also a frequent comorbidity in other chronic illnesses including neurological disorders, especially in multiple sclerosis. (2)

Multiple sclerosis (MS) is one of the most important causes of severe physical disability in young adults, usually being diagnosed between 20 and 40 years of age. $(3,4)$ Symptoms associated with multiple sclerosis are protean; patients may present motor deficits, ataxia, blurred vision, sensitive and sphincter disorders, and pain. The course of the disease is unpredictable. (3) In the past, phy- sicians tended to focus on the quantification of motor deficits and ambulation. In recent decades more attention has been paid to cognitive dysfunction, fatigue and mood disorders.

Psychiatric symptoms associated with MS were first described in detailed by Charcot in the nineteen century: pathological laughter, euphoria, mania, hallucinations and depression. However, it was only after 1950 that research on depression associated with multiple sclerosis really began. $(5,6)$

A diagnosis of multiple sclerosis can have a significant negative impact on the quality of life of patients. (7) The cause of depression in these patients is more complex than a simple reaction to a chronic progressive and disabling illness. Studies comparing the frequency of depression in patients with multiple sclerosis, amyotrophic lateral sclerosis and epilepsy have shown that the rate of depression is significantly higher in MS patients compared with the other two conditions (8). It seems that structural, immunological and neurochemical abnormalities also play an important role in the pathogenesis of depression in MS. (7) 


\section{EPIDEMIOLOGY}

The incidence and prevalence of depression among patients with MS vary according to the scales used for measurement, the characteristics of the studied population and the type of studies. Despite this variability the overall incidence is high and warrants special attention. The diagnosis of depression in MS is challenging because some symptoms of depression overlap with common symptoms of MS such as fatigue, cognitive dysfunction and insomnia. (9)

The lifetime prevalence of depression was found to be over $50 \%$ according to a structured psychiatric evaluation based on DSM-IV (by age 59 in patients with EDSS $\leq 6.5)$, but the real prevalence is probably higher. (10) The severity of MS has been shown to be a risk factor for depression. (11)

Joffe et al. reported a lifetime prevalence of $47 \%$ after analysing 100 consecutive patients with MS. (12) Minden et al. analysed data from 50 randomly selected MS patients and reported that $54 \%$ of them fulfilled the criteria for major depression. (13) Chwastiac et al. found that $42 \%$ of MS patients had clinically significant depression according to the CES-D score (Centre for Epidemiological Studies' Depression scale), $29 \%$ of them having moderate and severe symptoms. (11)

Depression is frequently also found in patients with early MS. According to Di Legge et al. 30\% of patients with clinically isolated syndrome (CIS) present depressive symptomatology. (14) Glanz et al. reported that $32 \%$ of CIS and newly diagnosed MS patients presented depression. (15)

The incidence of depression in MS significantly exceeds that of the general population and populations with other chronic medical illnesses, including neurological diseases with a high disability rate such as stroke. $(16,17,18)$ The reasons for this high incidence of depression in MS are multifaceted, ranging from simple ones such as the high disability rate to complex psychoneuroimmunological processes. (19)

\section{PATHOGENESIS}

The mechanisms that underlie the increased prevalence of depression in MS are controversial. From the simple psychological and psychosocial point of view the most important factors that contribute to the development of depression are the stress reaction following the diagnosis, the stress reaction to illness and disability, the prognostic uncertainty, the absence of appropriate social support, unemployment and inappropriate coping strategies. (20)

In recent years several papers have been published on the role of complex immunological mechanisms in the development of depression in MS. (21)

MS is an inflammatory demyelinating disease with mostly $\mathrm{T}$ cell-mediated immune dysfunction. Similarly with primary depression, patients with MS have high serum concentrations of proinflammatory cytokines. $(21,22)$

Several models that associate stress, cytokines, the endocrine system, and depression are presented in the literature. $(21,23,24)$

Depression has been associated with a dysfunctional, activated immune system. Depressed patients have increased activated $\mathrm{T}$ cell and acute phase protein levels, and a high rate of production of proinflammatory cytokines, such as interleukin (IL)-6, IL-1, tumour necrosis factor (TNF), and IFN- $\beta$. $(21,25-29)$

Significantly decreased TNF-alpha levels were found in depressed patients who responded favourably to amitriptyline therapy compared with nonresponders. $(21,30)$

Mohr et al. found that higher production of IFN- $\beta$ in patients with MS correlated with the severity of depression. Treatment of depression with both psycho- and pharmacotherapy decreased the production of IFN- $\beta$. $(21,31)$

According to O'Brien et al. cytokines modulate corticotropin-releasing hormone, which produces increased hypothalamic-pituitary-adrenal axis activity and increases the adrenocorticotropic hormone and cortisol level. $(21,23)$

The interaction of biological and psychological factors can exacerbate the depressive symptoms: the stress reaction activates the hypothalamus-pituitary-adrenal axis and the sympathetic nervous system, which stimulate the immune system to release inflammatory cytokines. (20) There is a dynamic relationship between neuroinflammation and depression. (20)

Structural brain changes on neuroimaging such as lesion location and cerebral atrophy are associated with the severity of depression. Lesions localized in the temporal lobe and hippocampal atrophy have been associated with depression possibly linked to the hypothalamic-pituitary-adrenal axis system. (32)

\section{ASSESSMENT}

The most important challenge in the correct diagnosis of depression in patients with multiple 
sclerosis is to interpret correctly the overlapping symptomatology such as fatigue, insomnia, altered appetite, memory and concentration impairment. Errors of judgement regarding these symptoms can lead to false negative and positive results. (5)

All patients with MS should be screened for depression during follow-up visits. A brief self-reported questionnaire validated for use in MS patients can be used as a screening tool. If the screening result is suggestive for depression a detailed follow-up interview is necessary to diagnose major depression. (32)

The most frequently recommended scales for screening are the Beck Fast Screen for depression and the Hospital Anxiety and Depression scale. (32)

Whooley et al. and Mohr et al. proposed a twoquestion instrument for screening, corresponding to depressive mood and anhedonia, and at least one affirmative response on either question was used as the diagnostic criteria. This assessment had a positive predictive value of $71.7 \%$. $(5,33,34)$

The most frequently used objective scales for depression in the MS population are the Beck Depression Inventory (BDI) and Center for Epidemiologic Studies Depression Rating Scale (CED-D). (5)

The BDI is a self-report instrument advocated as a useful screening measure for major depression, and consists of 21 items. The cutoff point is set at 13 . (35)

A shorter form was implemented and validated for MS patients comprising 7 items (Beck Depression Inventory Fast Screen). (36)

The CES-D rating scale is a 20 -item assessment tool comprising 20 items and is used with a cutoff point of 16. (37)

Other useful tools are the Hospital Anxiety and Depression Scale, Chicago Multiscale Depression Inventory, Hamilton rating Scale for Depression, Zung Self-Rating Depression Scale and Montgomery-Asberg Rating Scale. (5)

\section{CORRELATES OF DEPRESSION: DISABILITY, COGNITION, FATIGUE AND QUALITY OF LIFE}

The relationship between depression and disability in MS is controversial. Chwastiac et al. found a significant correlation between EDSS, as a global measure of physical impairment and depression in a population-based study, (11) but Bakshi et al. could not confirm this association. (38)

Williams et al. found a correlation between some components of overall disability such as bowel dysfunction and depression. (39)
According to recent studies patients with MS have a poorer quality of life (QoL) compared to the general population. This can be explained by the severity of the physical impairment but an important role seems to be played by neurobehavioural symptoms as well. (40)

Depression, cognitive impairment and fatigue are frequently named as the invisible manifestations of MS. Although these symptoms are frequently missed in a routine physical examination the overall well-being of a patient with MS cannot be fully understood without taking these symptoms into account, because each one could be the most disabling manifestation of the disease and the main determinant of the QoL (41).

Fatigue is the most common symptom reported by MS patients, with a prevalence ranging between $53-95 \%$ according to Krupp et al. (42)

For $40 \%$ of MS patients fatigue is the most disabling symptom, more so than weakness and ataxia, and can last for years. The symptoms of fatigue are very complex, but it is usually reported as a subjective feeling of tiredness, with a lack of energy that cannot be explained by physical or cognitive dysfunction. It is triggered by minimal or no effort, responds poorly to rest, affects daily activities, is chronic, is increased by high temperature and can appear at any stage of the disease. $(41,43)$

Understanding the relationship between depression and fatigue in MS patients is a challenging task for physicians because fatigue is a frequent symptom of depression. It is important to determine whether fatigue is a symptom of depression or a primary symptom of MS because the treatment options differ accordingly. (7) Other causes of secondary fatigue beside depression are: pain, anxiety, sleep disorders, anaemia or other metabolic disorders, and antispasticity medication. If fatigue is a manifestation of depression it is usually more severe in the morning. (41)

One of the first studies that reported a low but significant correlation between depression and fatigue was performed by Schwartz et al. on $139 \mathrm{MS}$ patients. $(44,45)$

Bakshi et al. found a highly significant correlation between these symptoms in MS patients, with depression seen more frequently in patients with fatigue and a correlation between the level of fatigue and the severity of depression. Fatigue was also reported by patients without depression, meaning that there must be other causes of fatigue in MS patients. $(46,47)$

In 2002 Janardhan \& Bakshi demonstrated that depression and fatigue are independent predictors of QoL. $(45,48)$ 
Despite studies performed in this field it is still not clear whether fatigue is a result of brain lesions or a psychological reaction to a chronic disease. (6)

Cognitive dysfunction is considered to be the most disabling symptom of MS because of its implication in the QoL of MS patients, as it affects the capacity to maintain employment, perform daily activities and remain socially engaged, and increases caregiver burden. (41) The prevalence of cognitive impairment in MS is over $40 \%$ and the most affected areas of cognition in such patients are: working, semantic and episodic memory, complex attention, information processing speed and executive functioning. The level of cognitive dysfunction can vary from slight memory impairment to dementia. $(6,7)$

Cognitive impairment appears in all MS subtypes including radiologically isolated syndrome, and in approximately $20 \%$ of patients with clinically isolated syndrome, and its prevalence is highest in the progressive form of MS. (41)

Depression associated with cognitive dysfunction can have an important negative impact on the QoL of MS patients. Recent studies revealed a reciprocal relationship between depression and cognitive impairment. Depression can induce concentration and attention problems and decrease information processing speed, but at the same time a MS patients that is aware of the decline in his cognitive function will have an increased level of anxiety and depression. A depressed patient will also overestimate his cognitive dysfunction thereby intensifying his depression. (49)

Randolph, Arnet \& Freske suggested that memory dysfunctions reported by MS patients are overestimated due to a depressive attitude. (50)

Pseudodementia is a term used in MS in cases in which a decreased level of attention, concentration and processing speed are symptoms of depression that may appear as a cognitive impairment but will improve after treatment for depression. $(51,52)$

Demaree and DeLuca demonstrated a significant correlation between severe depression and cognitive dysfunction. Arnett and colleagues reported a significant correlation between cognitive impairment and mood and negative self-evaluation. (53-56)

The link between depression and cognitive impairment is complicated because it seems to be bidirectional and further research is needed to understand this link.

\section{SUICIDE IN MULTIPLE SCLEROSIS}

Depression is one of the most important risk factors for suicidal ideation and suicide. Because of the high prevalence of depression among MS patients suicide risk must be considered in these patients. Statistical data indicate that the prevalence of suicide is several times higher in MS patients compared to the general matched population. (46)

Sadovnick and colleagues looked for the cause of death in a sample comprising $3126 \mathrm{MS}$ patients from two Canadian MS clinics, between 1972-1988. One hundred and forty-five deaths occurred in this period and in 119 cases they were able to identify the cause of death: 56 deaths $(47.1 \%)$ were due to direct MS complications. Among the 63 deaths that could not be attributed to MS complications, 18 (28.6\%) were due to suicide. According to this report the prevalence of suicide among MS patients was 7.5 times higher compared to the age-matched general population. (57)

A Danish study reported 53 suicides between 1953 and 1985 in 5525 MS patients. According to this study the suicide rate was higher in men and in patients in whom illness onset was before 30 years and the disease was diagnosed before 40 years. The suicide rate was higher in the first 5 years of the diagnosis. (58)

One hundred and forty consecutive patients were studied by Feinstein in a Canadian MS clinic. Of these patients $40(28.6 \%)$ experienced suicidal intent and 9 (6.4\%) actually attempted suicide. He found a significant correlation between suicidal intent and severity of depression, alcohol abuse and social isolation. This association had an $85 \%$ predictive accuracy for suicidal intent in the studied MS population.

The higher rate of suicide in patients with MS compared with the general population or patients with other neurological diseases can be explained by a higher prevalence of depression in MS patients associated with neurological disability at younger ages. (59)

Suicide prevalence in MS patients can be reduced by early detection of depression and suicidal ideation and adequate treatment. (7)

\section{DEPRESSION AND IMMUNOMODULATORY THERAPY}

The relationship between depression in MS and immunomodulatory treatment is controversial. The suspicion that interferon beta can cause or exacerbate depression was first raised after the first clinical trial in the early 1990s. The study reported one suicide and four suicide attempts in the treated group. $(6,60)$ 
The results of another clinical trial, this time involving IFN beta-1a, the Controlled High-Risk Subjects Avonex Multiple Sclerosis Prevention Study (CHAMPS), also reported higher levels of depression among the treated group (20\%) compared to the placebo group (13\%). (61)

In a longitudinal study Arnet and Randolph found that patients with an increased level of depression compared to baseline were more likely to have been treated with interferon. (62)

On the other hand recent studies do not support this theory. No significant correlations were found between treated and placebo groups regarding depression rates in the study "Prevention of Relapses and Disability by Interferon beta 1-a Subcutaneously in MS" (PRISMS) and "Secondary Progressive Efficacy Trial of Rebif in MS" (SPECTRIMS). The authors suggested that the depression levels were more closely correlated with pretreatment depressed mood. $(6,63,64)$

Zephir et al. demonstrated that treatment with intramuscular IFN beta 1a was not associated with a significant increase in depression rates. The same results were obtained by Feinstein et al. in a cohort treated with IFN beta-1b. $(65,66)$

According to these studies there is no clear indication for stopping treatment with IFN in MS patients with depression due to the fear of exacerbating depression. In cases in which depression rates are increased under treatment with IFN an alternative treatment is glatiramer acetate. Glatiramer acetate increases the production of brain-derived neurotrophic factor, which seems to have a theoretical benefit in depression. (7)

\section{DEPRESSION AND NEUROIMAGING}

The link between brain lesions and depression was first demonstrated by Schiffer et al. in 1983 and by Rabins et al. in 1986, both of whom examined the computed tomography (CT) scans of patients with MS. They found that depression rates were higher in patients with brain lesions compared with patients that only had spinal cord lesions. (67, $68,69)$

Whether lesions located in certain brain regions correlate with depression in patients with MS has generated numerous debates, and formed the basis of several studies.

In 1997 Pujol et al. evaluated 45 consecutive MS patients in a clinic in Barcelona for depression using BDI. Seven of these patients had moderate and severe depression, meaning a BDI score greater than 17. A standardized magnetic resonance im- aging (MRI) protocol performed in all patients revealed a significant correlation between depression and lesions located in the arcuate fasciculus of the left hemisphere, but no relation between depression and total lesion volume. $(6,70)$

More recent studies tried to find a correlation not only between depression and lesion location but also between depression and brain atrophy. Zorzon et al. performed a study on 95 MS patients, of which $18(19 \%)$ met the criteria for major depression. He reported a significant correlation between the severity of depression and the number of lesions in the right frontal lobe, the total temporal volume, right temporal and right hemisphere volume. $(6,71)$

Feinstein et al. compared the MRI findings of a group of 21 depressed MS and a group of 19 nondepressed MS patients. He found that depressed patients have more hyperintense lesions in left inferior medial frontal regions and greater atrophy of left anterior temporal regions. (72)

The first to look at hypointense T1 lesions in MS and to try to find a relationship with depression was Bakshi et al. He reported a significant correlation between depression and $\mathrm{T} 1$ lesions in the superior frontal, superior parietal and temporal lobes but also with lateral and third ventricle enlargement and frontal atrophy. $(21,38)$

On the other hand, in a large study performed on 123 MS patients Clark et al. found no significant correlation between depression level and ventricular enlargement. (73)

According to these studies the relationship between the brain lesions demonstrated on imaging and depression is related to damage of particular areas of the brain (left anterior temporal and parietal lesions) or the interruption of particular pathways.

\section{TREATMENT OPTIONS}

The treatment of depression in MS is a great challenge and depression appears to be under-diagnosed and under-treated, (20) despite the fact that correctly treated patients present a significant improvement in life quality, functional status, selfesteem and compliance with immunomodulatory treatment. $(74,75,76)$

Untreated depression in MS presents a worsening tendency over time. (77)

Sollom et al. analysed data from 495 MS patients, and found that while $60 \%$ of patients presented with significant depressive symptomatology, only $26.2 \%$ of them were treated for depression. 
The majority of treated patients only had treatment recommended by their general practitioner and were not referred to a psychiatrist. The authors concluded that this is an important issue because of the risk of side effects and drug interactions. (78)

The therapeutic interventions with proven efficacy in depressive patients with MS include pharmacological treatment, psychotherapeutic interventions and exercise. (20)

The use of antidepressive medication in MS is common, but there are few data in the literature about their effectiveness. (20)

Based on data from a controlled clinical trial Schiffer et al. proved the effectiveness of the tricyclic antidepressant desimipramine. (79)

Other small trials have demonstrated the effectiveness of sertraline (80) and paroxetine (81) over placebo.

A Cochrane review based on data from two randomized trials proved that paroxetine and desimipramine showed a trend toward efficacy in the treatment of depression associated with MS. The most frequent adverse effects were nausea and headache. (82)

According to Serafin et al. the use of tricyclic antidepressants requires caution due to anticholinergic side effects that can worsen sphincter dysfunction (urinary retention and constipation) and cognition, but can be used for detrusor spasm. The tricyclic desimipramine and the SSRI paroxetine can be useful for sedative and appetite-stimulating effects in some cases. The tricyclic antidepressants and the SNRI duloxetine may be beneficial in pain syndromes associated with MS. The SSRIs are usually well tolerated, and the drug interaction profile is more favourable in the case of citalopram and escitalopram. In cases of fatigue and sexual dysfunction, which can be exacerbated by some SSRIs, the use of bupropion and SNRIs (venlafaxine) may be safer. (7)

There are several psychotherapeutic methods that are used for the treatment of depression in MS. Cognitive behavioural therapy is most frequently used. One of the challenges in this field is that the effectiveness of psychotherapy is highly variable depending on the knowledge and training of the provider, the frequency and duration of the therapeutic meetings, and the inclusion of others such as family members. (46)

Several randomized trials have demonstrated the effectiveness of cognitive behavioural therapy (CBT) for the treatment of depression in MS, (80) with response rates to $\mathrm{CBT}$ being equal to or higher than response rates to antidepressant medication and other psychotherapeutic methods. (80)

The Goldman Consensus group recommended that CBT can be used as a treatment option for patients with MS and depression. (83)

Physical exercise is beneficial in several complications of MS, including mood disorders, pain, fatigue, quality of life, sexual dysfunction, recreation and psychosocial problems. (84)

In addition, relapse into depression is lower in MS patients who undertake regular physical exercise. (85)

\section{REFERENCES}

1. Hecimovic H. Neurobiological aspects of depression: how do they affect neurologic disorders? In: Kanner AM. Depression in neurological disorders: diagnosis and management. Oxford: Wiley-Blackwell, 2002: 10-27

2. Kalkut E.J., Grote C.L. Neuropsychological aspects of depression: their relevance in depression in neurologic disorders. In: Kanner AM. Depression in neurological disorders: diagnosis and management. Oxford: Wiley-Blackwell, 2002:10-27

3. Luzzio C. (2014, Nov 24). Multiple Sclerosis. eMedicine.Medscape. Retrieved 11/25/2014 from http://emedicine.medscape.com/ article/1146199-overview

4. Reese J.P., Wienemann G., John A., Linnemann A., BalzerGeldsetzer M., Mueller U.O., Eienbröker C., Tackenberg B., Dodel R. Preference-based Health status in a German outpatient cohort with multiple sclerosis. Health Qual Life Outcomes; 2013; 11:162.

5. Skokou M., Soubasi E., Gourzis P. Depression in multiple sclerosis: a review of assessment and treatment approaches in adult and pediatric populations. ISRN Neurol. 2012; 2012:427102.

6. Siegert R.J., Abernethy D.A. Depression in multiple sclerosis: a review. J Neurol Neurosurg Psychiatry. 2005 Apr; 76(4):469-75.

7. Serafin D.J., Weisbrot D.M., Ettinger A.B. Depression and Multiple Sclerosis In: Kanner AM, Depression in Neurologic Disorders: Diagnosis and Management. Oxford: Wiley-Blackwell 2012: 157-176

8. Schiffer R.B., Babigian H.M. Behavioral disorders in multiple sclerosis, temporal lobe epilepsy, and amyotrophic lateral sclerosis. An epidemiologic study. Arch Neurol. 1984 Oct; 41(10):1067-9.

9. Patten S. Diagnosing Depression in MS in the Face of Overlapping Symptoms. Int MS J. 2010 Jan; 17(1):3-5.

10. Sadovnick A.D., Remick R.A., Allen J., Swartz E., Yee I.M., Eisen K., Farquhar R., Hashimoto S.A., Hooge J., Kastrukoff L.F., Morrison W., Nelson J., Oger J., Paty D.W. Depression and multiple sclerosis. Neurology. 1996 Mar; 46(3):628-32.

11. Chwastiak L., Ehde D.M., Gibbons L.E., Sullivan M., Bowen J.D., Kraft GH.Depressive symptoms and severity of illness in multiple sclerosis: epidemiologic study of a large community sample. Am J Psychiatry. 2002 Nov;159(11):1862-8. 
12. Joffe R.T., Lippert G.P., Gray T.A., Sawa G., Horvath Z. Mood disorder and multiple sclerosis. Arch Neurol. 1987 Apr; 44(4):376-8.

13. Minden S.L., Schiffer R.B. Affective disorders in multiple sclerosis. Review and recommendations for clinical research. Arch Neurol. 1990 Jan; 47(1):98-104.

14. Di Legge S., Piattella M.C., Pozzilli C., Pantano P., Caramia F., Pestalozza I.F., Paolillo A., Lenzi G.L. Longitudinal evaluation of depression and anxiety in patients with clinically isolated syndrome at high risk of developing early multiple sclerosis. Mult Scler. 2003 Jun;9(3):302-6.

15. Glanz B.I., Holland C.M., Gauthier S.A., Amunwa E.L., Liptak Z., Houtchens M.K., Sperling R.A., Khoury S.J., Guttmann C.R., Weiner H.L. Cognitive dysfunction in patients with clinically isolated syndromes or newly diagnosed multiple sclerosis. Mult Scler. 2007 Sep; 13(8):1004-10.

16. Kessler R.C., Gruber M., Hettema J.M., Hwang I., Sampson N., Yonkers K.A. Co-morbid major depression and generalized anxiety disorders in the National Comorbidity Survey follow-up. Psychol Med. 2008 Mar; 38(3):365-74

17. Patten S.B., Beck C.A., Williams J.V., Barbui C., Metz L.M. Major depression in multiple sclerosis: a population-based perspective. Neurology. 2003 Dec 9; 61(11):1524-7.

18. Egede L.E. Major depression in individuals with chronic medical disorders: prevalence, correlates and association with health resource utilization, lost productivity and functional disability. Gen Hosp Psychiatry. 2007 Sep-Oct; 29(5):409-16.

19. Gold S.M., Irwin M.R. Depression and immunity: inflammation and depressive symptoms in multiple sclerosis. Immunol Allergy Clin North Am. 2009 May; 29(2):309-20.

20. Siracusano A., Niolu C., Sachetti L., Ribolsi M. Depression and Anxiety in Nocentini U, Caltagirone C, Tedeschi G. Neuropsychiatric dysfunction in multiple sclerosis. Italia: Springer-Verlag, 2012

21. Wallin M.T., Wilken J.A., Turner A.P., Williams R.M., Kane R. Depression and multiple sclerosis: Review of a lethal combination. J Rehabil Res Dev. 2006 Jan-Feb; 43(1):45-62.

22. Mikova O., Yakimova R., Bosmans E., Kenis G., Maes M. Increased serum tumor necrosis factor alpha concentrations in major depression and multiple sclerosis. Eur Neuropsychopharmacol. 2001; 11(3):203-8.

23. O'Brien S.M., Scott L.V., Dinan T.G. Cytokines: Abnormalities in major depression and implications for pharmacological treatment. Hum Psychopharmacol. 2004; 19(6): 397-403.

24. Dubas-Slemp H., Marmurowska-Michalowska H., SzusterCiesielska A., Kaminska T., Kandefer-Szerszen M. The role of cytokines in depression [Polish]. Psychiatr Pol. 2003; 37(5):787-98.

25. Sluzewska A., Rybakowski J., Bosmans E., Sobieska M., Berghmans R., Maes M., Wiktorowicz K. Indicators of immune activation in major depression. Psychiatry Res. 1996; 64(3):161-67.

26. Frommberger U.H., Bauer J., Haselbauer P., Fraulin A., Riemann D., Berger M. Interleukin-6 (IL-6) plasma levels in depression and schizophrenia: comparison between the acute state and after remission. Eur Arch Psychiatry Clin Neurosci. 1997; 247(4):228-33.

27. Owen B.M., Eccleston D., Ferrier I.N., Young A.H. Raised levels of plasma interleukin-1 in major and postviral depression. Acta Psychiatr Scand. 2001; 103(3):226-28.

28. Penninx B.W., Kritchevsky S.B., Yaffe K., Newman A.B., Simonsick E.M., Rubin S., Ferrucci L., Harris T., Pahor M. Inflammatory markers and depressed mood in older persons: results from the Health, Aging and Body Composition study. Biol Psychiatry. 2003; 54(5):566-72.

29. Seidel A., Arolt V., Hunstiger M., Rink L., Behnisch A., Kirchner H. Cytokine production and serum proteins in depression. Scand J Immunol. 1995; 41(6):534-38.

30. Lanquillon S., Krieg J.C., Bening-Abu-Shach U., Vedder H. Cytokine production and treatment response in major depressive disorder. Neuropsychopharmacology. 2000; 22(4):370-79.

31. Mohr D.C., Goodkin D.E., Islar J., Hauser S.L., Genain C.P. Treatment of depression is associated with suppression of nonspeci- fic and antigen-specific $\mathrm{T}(\mathrm{H}) 1$ responses in multiple sclerosis. Arch Neurol. 2001; 58(7):1081-86.

32. Charvet L.E., Kluzer B., Krupp L.B. Invisible symptoms of MS: Fatigue, Depression, and Cognition. In Samkoff LM, Goodman AD. Multiple Sclerosis and CNS Inflammatory Disorders. Oxford: Wiley Blackwell, 2014.

33. Whooley M.A., Avins A.L., Miranda J., Browner W.S. Case-finding instruments for depression. Two questions are as good as many. J Gen Intern Med. 1997 Jul; 12(7):439-45.

34. Mohr D.C., Hart S.L., Julian L., Tasch E.S. Screening for depression among patients with multiple sclerosis: two questions may be enough. Mult Scler. 2007 Mar; 13(2):215-9.

35. Beck A.T., Ward C.H., Mendelson M., Mock J., Erbaugh J. An inventory for measuring depression. Arch Gen Psychiatry. 1961 Jun; 4:561-71.

36. Benedict R.H., Fishman I., McClellan M.M., Bakshi R., WeinstockGuttman B. Validity of the Beck Depression Inventory-Fast Screen in multiple sclerosis. Mult Scler. 2003 Aug; 9(4):393-6.

37. McDowell I. Measuring Health, a Guide to Rating scales and Qyestionnaires, New York: Oxford University Press, 1996

38. Bakshi R., Czarnecki D., Shaikh Z.A., Priore R.L., Janardhan V., Kaliszky Z., Kinkel P.R. Brain MRI lesions and atrophy are related to depression in multiple sclerosis. Neuroreport. $2000 \mathrm{Apr}$ 27;11(6):1153-8.

39. Williams R.M., Turner A.P., Hatzakis M. Jr, Bowen J.D., Rodriquez A.A., Haselkorn J.K. Prevalence and correlates of depression among veterans with multiple sclerosis. Neurology. 2005 Jan 11; 64(1):75-80.

40. Janssens A.C., van Doorn P.A., de Boer J.B., Kalkers N.F., van der Meche F.G., Passchier J., Hintzen R.Q. Anxiety and depression influence the relation between disability status and quality of life in multiple sclerosis. Mult Scler. 2003 Aug; 9(4):397-403.

41. Charvet L.E., Kluzer B., Krupp L.B. Invisible symptoms of MS: Fatique, Depression, and Cognition in Samkoff LM, Goodman AD, Multiple Sclerosis and CNS Inflammatory Disorders, Oxford: Wiley Blackwell, 2014: 114-121

42. Krupp L.B., Alvarez L.A., LaRocca N.G., Scheinberg L.C. Fatigue in multiple sclerosis. Arch Neurol. 1988 Apr; 45(4):435-7.

43. Miletic S., Toncev G., Jevdjic J., Jovanovic B. and Canovic D. Fatigue and depression in multiple sclerosis: correlation with quality of life. Arch. Biol. Sci., Belgrade, 63 (3), 617-622, 2011

44. Schwartz C.E., Coulthard-Morris L., Zeng Q. Psychosocial correlates of fatigue in multiple sclerosis. Arch Phys Med Rehabil. 1996 Feb; 77(2):165-70.

45. Jefferies $\mathrm{K}$. The neuropsychiatry of multiple sclerosis. Advances in Psychiatric Treatment. 2006; 12: 214-220

46. Rintell D.J. Depression and Other Psychosocial Issues in Multiple Sclerosis in Weiner HL, Stankiewicz JM, Multiple Sclerosis Diagnosis and Therapy, Oxford: Wiley-Blackwell, 2012: 263-282

47. Bakshi R., Shaikh Z.A., Miletich R.S., Czarnecki D., Dmochowski J., Henschel K., Janardhan V., Dubey N., Kinkel P.R. Fatigue in multiple sclerosis and its relationship to depression and neurologic disability. Mult Scler. 2000 Jun; 6(3):181-5.

48. Janardhan V., Bakshi R. Quality of life in patients with multiple sclerosis: the impact of fatigue and depression. J Neurol Sci. 2002 Dec 15; 205(1):51-8.

49. Sahraian M.A., Etesam F. Cognitive Impairment in Multiple Sclerosis. ZJRMS 2014; 16(1):1-7

50. Randolph J.J., Arnett P.A., Freske P. Metamemory in multiple sclerosis: exploring affective and executive contributors. Arch Clin Neuropsychol. 2004 Mar; 19(2):259-79.

51. Sachdev P.S., Smith J.S., Angus-Lepan H., Rodriguez P. Pseudodementia twelve years on. J Neurol Neurosurg Psychiatry. 1990 Mar; 53(3):254-9.

52. Sperling R.A., Guttmann C.R., Hohol M.J., Warfield S.K., Jakab M., Parente M., Diamond E.L., Daffner K.R., Olek M.J., Orav E.J., Kikinis R., Jolesz F.A., Weiner H.L. Regional magnetic resonance imaging lesion burden and cognitive function in multiple sclerosis: a longitudinal study. Arch Neurol. 2001 Jan; 58(1):115-21. 
53. Arnett P.A., Higginson C.I., Randolph J.J. Depression in multiple sclerosis: relationship to planning ability. J Int Neuropsychol Soc2001; 7:665-74.

54. Demaree H.A., Gaudino E., DeLuca J. The relationship between depressive symptoms and cognitive dysfunction in multiple sclerosis. Cogn Neuropsychiatry 2003; 8:161-71.

55. Demaree H.A., DeLuca J., Gaudino E., et al. Speed of information processing as a key deficit in multiple sclerosis. J Neurol Neurosurg Psychiatry 1999; 67:661-3.

56. DeLuca J., Gaudino E.A., Diamond B.J., et al. Acquisition and storage deficits in multiple sclerosis. J Clin Exp Neuropsychol 1998; 20:376-90.

57. Sadovnick A.D., Eisen K., Ebers G.C., et al. Cause of death in patients attending multiple sclerosis clinics. Neurology 1991; 41:1193-6.

58. Stenager E.N., Stenager E., Koch-Henricksen N., et al. Suicide and multiple sclerosis: an epidemiological investigation. J Neurol Neurosurg Psychiatry 1992; 55:542-5.

59. Feinstein A . An examination of suicidal intent in patients with multiple sclerosis. Neurology 2002; 59:674-8.

60. Klapper M.D. Letter to the editor [letter]. Neurology 1994;44:188

61. Jacobs L.D., Beck R.W., Simon J.H., Kinkel R.P., Brownscheidle C.M., Murray T.J., Simonian N.A., Slasor P.J., Sandrock A.W. Intramuscular interferon beta-1a therapy initiated during a first demyelinating event in multiple sclerosis. CHAMPS Study Group. N Engl J Med. 2000 Sep 28; 343(13):898-904.

62. Arnett P.A., Randolph J.J. Longitudinal course of depression symptoms in multiple sclerosis. J Neurol Neurosurg Psychiatry. 2006 May; 77(5):606-10.

63. Patten S.B., Metz L.M. Interferon beta-1 a and depression in relapsing-remitting multiple sclerosis: an analysis of depression data from the PRISMS clinical trial. Mult Scler. 2001 Aug; 7(4):243-8.

64. Patten S.B., Metz L.M. SPECTRIMS Study Group.Interferon beta1a and depression in secondary progressive MS: data from the SPECTRIMS Trial. Neurology. 2002 Sep 10; 59(5):744-6.

65. Zephir H., De Seze J., Stojkovic T., Delisse B., Ferriby D., Cabaret M., Vermersch P. Multiple sclerosis and depression: influence of interferon beta therapy. Mult Scler. 2003 Jun; 9(3):284-8.

66. Feinstein A., O'Connor P., Feinstein K. Multiple sclerosis, interferon beta- $1 \mathrm{~b}$ and depression $\mathrm{A}$ prospective investigation. J Neurol. 2002 Jul; 249(7):815-20.

67. Feinstein A. The Clinical Neuropsychiatry of MS. Cambridge University Press, Cambridge 2007, pg 46-65

68. Schiffer R.B., Caine E.D., Bamford K.A., Levy S. Depressive episodes in patients with multiple sclerosis. Am J Psychiatry. 1983 Nov; 140(11):1498-1500.

69. Rabins P.V., Brooks B.R., O'Donnell P., Pearlson G.D., Moberg P., Jubelt B., Coyle P., Dalos N., Folstein M.F. Structural brain correlates of emotional disorder in multiple sclerosis. Brain. 1986 Aug; 109 ( Pt 4):585-97.
70. Pujol J., Bello J., Deus J., Martí-Vilalta J.L., Capdevila A. Lesions in the left arcuate fasciculus region and depressive symptoms in multiple sclerosis. Neurology. 1997 Oct; 49(4):1105-10.

71. Zorzon M., de Masi R., Nasuelli D., Ukmar M., Mucelli R.P., Cazzato G., Bratina A., Zivadinov R. Depression and anxiety in multiple sclerosis. A clinical and MRI study in 95 subjects. J Neurol. 2001 May; 248(5):416-21.

72. Feinstein A., Roy P., Lobaugh N., Feinstein K., O'Connor P., Black S. Structural brain abnormalities in multiple sclerosis patients with major depression. Neurology. 2004 Feb 24; 62(4):586-90.

73. Clark C.M., James G., Li D., Oger J., Paty D., Klonoff H. Ventricular size, cognitive function and depression in patients with multiple sclerosis. Can J Neurol Sci. 1992 Aug; 19(3):352-6.

74. Mohr D.C., Goodkin D.E., Gatto N., et al. Depression, coping and level of neurological impairment in multiple sclerosis.

Mult Scler, 3 (4):254-258, 1997.

75. Thomas P.W., Thomas S., Hillier C., et al. Psychological inter ventions for multiple sclerosis. Cochrane Database Syst Rev, (1): CD004431, 2006

76. Mohr D.C., Goodkin D.E., Likosky W., et al. Treatment of depression improves adherence to inter feron beta - $1 \mathrm{~b}$ therapy for multiple sclerosis. Arch Neurol, 54 (5):531-533, 1997.

77. Mohr D., Goodkin D.E. Treatment of depression in multiple sclerosis: review and meta-analysis. Clin Psychol: Sci Pract, 6:1- 9, 1999.

78. Sollom A.C., Kneebone I.I. Treatment of depression in people who have multiple sclerosis. Mult Scler, 13 (5): 632-635, 2007.

79. Schiffer R.B., Wineman N.M. Antidepressant pharmacotherapy of depression associated with multiple sclerosis. Am J Psychiatry, 147 (11): $1493-1497,1990$.

80. Mohr D.C., Boudewyn A.C., Goodkin D.E., et al. Comparative outcomes for individual cognitive - behavior therapy, supportive - expressive group psychotherapy, and ser traline for the treatment of depression in multiple sclerosis. J Consult Clin Psychol, 69 (6): 942-949, 2001.

81. Ehde D.M., Kraft G.H., Chwastiak L., et al. Efficacy of paroxetine in treating major depressive disorder in persons with multiple sclerosis. Gen Hosp Psychiatry, 30 (1):40-48, 2008.

82. Koch M.W., Glazenborg A., Uyttenboogaart M., Mostert J., De Keyser J. Pharmacologic treatment of depression in multiple sclerosis. Cochrane Database Syst Rev. 2011 Feb 16;(2):CD007295.

83. Goldman Consensus Group. The Goldman Consensus statement on depression in multiple sclerosis. Mult Scler. 2005 Jun; 11(3):328-37.

84. Petajan J.H., Gappmaier E., White A.T., Spencer M.K., Mino L., Hicks R.W. Impact of aerobic training on fitness and quality of life in multiple sclerosis. Ann Neurol. 1996 Apr; 39(4):432-41.

85. Brown T.R., Kraft G.H. Exercise and rehabilitation for individuals with multiple sclerosis. Phys Med Rehabil Clin N Am. 2005 May; 16(2):513-55. 